Tropical Journal of Pharmaceutical Research October 2010; 9 (5): 499-503

(C) Pharmacotherapy Group, Faculty of Pharmacy, University of Benin

Benin City, 300001 Nigeria.

All rights reserved.

Research Article

Available online at http://www.tjpr.org

\title{
Spectrophotometric Determination of Cilostazol in Tablet Dosage Form
}

\author{
Pawan Kumar Basniwal ${ }^{1 *}$, Vinesh Kumar ${ }^{1}$, Prabhat Kumar \\ Shrivastava ${ }^{2}$ and Deepti Jain ${ }^{3}$ \\ ${ }^{1}$ LBS College of Pharmacy, Tilak Nagar, Jaipur - 302004, Rajasthan, ${ }^{2}$ Department of Pharmaceutics, Banaras Hindu \\ University, Banaras, UP, ${ }^{3}$ School of Pharmaceutical Sciences, Rajiv Gandhi Technical University, Bhopal (MP), India
}

\begin{abstract}
Purpose: To develop simple, rapid and selective spectrophotometric methods for the determination of cilostazol in tablet dosage form.

Methods: Cilostazol was dissolved in $50 \%$ methanol and its absorbance was scanned by ultraviolet (UV) spectrophotometry. Both linear regression equation and standard absorptivity were calculated and both methods were validated as per ICH guidelines. Cilostazol was determined in tablet dosage form using these validated methods.

Results: The $\lambda_{\max }$ of cilostazol was $258.2 \mathrm{~nm}$ in $50 \%$ methanol. Beer-Lambert's law was obeyed in the concentration range of $0-25 \mu \mathrm{g} / \mathrm{ml}$ and standard absorptivity was $420.2 \mathrm{dL} . \mathrm{g}^{-1} . \mathrm{cm}^{-1}$. The numerical values for all the validation parameters were within acceptable limits. The results of cilostazol tablet determination by linear regression equation and standard absorptivity methods indicate purity of 100.0 102.4 and 98.7 - $101.1 \%$ with standard deviations of 0.611 and 0.592, respectively. Comparing the methods at $99 \%$ confidence limit, the F-test value was found to be 1.065 .

Conclusion: These validated methods may be useful for routine analysis of cilostazol as bulk drugs, in dosage forms as well as in dissolution studies in the pharmaceutical industry.
\end{abstract}

Keywords: Cilostazol tablets, UV spectrophotometry, Linear regression equation, Standard absorptivity. 


\section{INTRODUCTION}

Cilostazol, whose chemical name is 6-[4-(1cyclohexyl-1H-tetrazol-5-y1) butoxy]-3, 4dihydro-2 $(1 \mathrm{H})$ - quinolinone (see Fig 1 ), is a quinolinone derivative that inhibits cellular phosphodiesterase III, and is used for the inhibition of platelet aggregation and as a vasodilator [1-4].

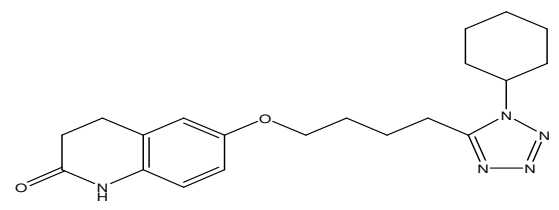

Fig. 1: Structure of cilostazol

The literature reveals that chromatographic methods are employed in the determination of cilostazol in tablet dosage form and human plasma and, to the best of our knowledge, no spectrophotometric method has yet been reported for this compound in tablet form [56]. However, the degradation profile and RPHPLC analysis of cilostazol in tablet dosage form has been reported [7]. Compared to chromatographic methods, spectrophotometric methods are suitable for routine analysis because it is economic, rapid, simple, maintenance-free, and show comparable accuracy and precision with HPLC methods. Therefore, the object of the present work was to develop spectrophotometric methods for the determination of cilostazol in tablet form.

\section{EXPERIMENTAL}

\section{Instruments, reagents and chemicals}

Ultraviolet spectrophotometer (1700 series, Shimadzu) and UV-VIS double beam spectrophotometer 2201 (Systronics) with 1 $\mathrm{cm}$ matched quartz cells were used for the measurement of absorbance. Shimadzu-Ax200 electronic balance was used for weighing the samples, and class "A" volumetric glassware were used.
Working standard (WS) of cilostazol was a gift from IPCA Laboratories Ltd, Ratlam, MP, India, while Pletoz ${ }^{\circledR} 50$ tablets (cilostazol tablets $50 \mathrm{mg}$ ) manufactured by Hetero Drugs Ltd, Hyderabad were procured from a local pharmacy. Methanol AR grade (Merck, India) and distilled water were used for analytical work.

\section{Linear regression equation method}

Stock A (500 $\mu \mathrm{g} / \mathrm{ml}$ cilostazol) was prepared from accurately weighed $50 \mathrm{mg}$ cilostazol WS in $50 \%$ aqueous methanol. It was diluted with the solvent to produce Stock B (50 $\mu \mathrm{g} / \mathrm{ml})$; aliquots of Stock B were further diluted to give concentrations of $5,10,15,20$ and $25 \mu \mathrm{g} / \mathrm{ml}$ of cilostazol, respectively. These dilutions were scanned from 300 to $200 \mathrm{~nm}$ against $50 \%$ aqueous methanol as blank, and their absorbances observed at $258.2 \mathrm{~nm}$.

\section{Standard absorptivity method}

Five dilutions of cilostazol were prepared in triplicate and their absorbances were observed at $258.2 \mathrm{~nm}$. From the above observations, the standard absorptivity, A $(1 \%, 1 \mathrm{~cm})$, and molar extinction coefficient were calculated.

\section{Validation of methods}

As per $\mathrm{ICH}$ guidelines [8-9], six dilutions in triplicate were used to validate both methods for linearity, accuracy (by recovery studiesstandard addition to pre-analysed samples), repeatability (within day), intermediate precision (days, analyst and instrument variation) and robustness (methanol variation: 45,50 and $55 \%$ ), and statistical parameters were calculated for them.

\section{Quantitative determination}

Twenty cilostazol tablets were weighed and finely powdered; a quantity equivalent to 50 $\mathrm{mg}$ of cilostazol was dissolved in $100 \mathrm{ml}$ of 50 $\%$ aqueous methanol and filtered through 
Whatman filter paper no. 41 to give Stock $P$. Stock $P$ was diluted to obtain Stock $Q$ (50 $\mu \mathrm{g} / \mathrm{ml})$. Aliquots of Stock $Q$ were diluted to obtain sample concentrations in the range of linearity. The absorbance values of these sample solutions were observed in a multipoint calibration curve of quantitative mode at the selected wavelength $(258.2 \mathrm{~nm})$ to obtain test sample concentration.

\section{RESULTS}

The linear regression equation obtained from analyzing standard solutions of cilostazol is shown in Eq 1.

$A B C=0.2069 C-0.204$

It showed an $r^{2}=0.9999$ where $A B C=$ absorbance, $C=$ concentration $(\mu \mathrm{g} / \mathrm{ml})$, and $\mathrm{r}^{2}$ $=$ correlation coefficient. The standard absorptivity, A $(1 \%, 1 \mathrm{~cm})$, and molar extinction coefficient $(\varepsilon)$ for cilostazol were $420.23 \mathrm{dlg}^{-1} \mathrm{~cm}^{-1}$ and $15527.51 \mathrm{Mol}^{-1} \mathrm{~cm}^{-1}$, respectively (see Table 1). These developed methods were validated for various parameters, viz, accuracy, precision (repeatability, intermediate precision for days, instrument and analysts) and robustness. Statistical analysis (SD, CV, SEx and SE $\sigma$ ) for validation parameters are summarized in Table 2. These parameters were less than one. Thus, these parameters show the suitability of the methods.

Table 1: Standard absorptivity, A $(1 \%, 1 \mathrm{~cm})$, and molar extinction coefficient $(\varepsilon)$ for cilostazol

\begin{tabular}{|c|c|c|c|c|c|c|}
\hline \multirow{2}{*}{$\begin{array}{l}\text { Conc. } \\
(\mu \mathrm{g} / \mathrm{ml})\end{array}$} & \multicolumn{3}{|c|}{$\begin{array}{c}\text { Absorbance at } 258.2 \\
\mathrm{~nm}\end{array}$} & \multicolumn{3}{|c|}{$\begin{array}{r}\text { Standard absorptivity } \\
\{\mathrm{A}(1 \%, 1 \mathrm{~cm})=\mathrm{A} / \mathrm{bc}\}\end{array}$} \\
\hline & $\mathbf{I}$ & II & III & I & II & III \\
\hline 5 & 0.211 & 0.209 & 0.210 & 422.0 & 418.0 & 420.0 \\
\hline 10 & 0.422 & 0.424 & 0.419 & 422.0 & 424.0 & 419.0 \\
\hline 15 & 0.630 & 0.628 & 0.632 & 420.0 & 418.7 & 421.3 \\
\hline 20 & 0.835 & 0.842 & 0.840 & 417.5 & 421.0 & 420.0 \\
\hline 25 & 1.052 & 1.050 & 1.048 & 420.8 & 420.0 & 419.2 \\
\hline \multicolumn{7}{|c|}{$\mathrm{A}(1 \%, 1 \mathrm{~cm})^{*} \quad 420.23 \mathrm{dlg}^{-1} \mathrm{~cm}^{-1}$} \\
\hline \multicolumn{7}{|c|}{$\varepsilon^{* *} \quad 15527.51 \mathrm{Mol}^{-1} \mathrm{~cm}^{-1}$} \\
\hline
\end{tabular}

Table 2: Results of validation parameters for cilostazol

\begin{tabular}{|c|c|c|c|c|c|}
\hline Validation parameter & $\begin{array}{l}\% \text { found }^{*} \\
\text { (mean) }\end{array}$ & SD & CV & SEx & SE $\sigma$ \\
\hline \multicolumn{6}{|c|}{ Linear regression equation (LRE) method } \\
\hline Linearity & 100.47 & 0.0106 & 0.3238 & 0.0047 & 0.0033 \\
\hline Accuracy & 100.08 & 0.1603 & 0.1603 & 0.0653 & 0.0460 \\
\hline \multicolumn{6}{|l|}{ Precision } \\
\hline I. Repeatability & 100.92 & 0.0820 & 0.5056 & 0.0366 & 0.0259 \\
\hline \multicolumn{6}{|l|}{$\begin{array}{l}\text { II. Intermediate } \\
\text { precision }\end{array}$} \\
\hline a. Days & 101.13 & 0.0620 & 0.4548 & 0.0277 & 0.0196 \\
\hline b. Analysts & 100.86 & 0.0540 & 0.3954 & 0.0241 & 0.0170 \\
\hline c. Instruments & 100.34 & 0.6145 & 0.6625 & 0.2705 & 0.1910 \\
\hline Robustness & 100.46 & 0.6733 & 0.6680 & 0.3013 & 0.2130 \\
\hline \multicolumn{6}{|c|}{ Standard absorptivity (SA) method } \\
\hline Accuracy & 100.12 & 0.2216 & 0.2210 & 0.0903 & 0.0636 \\
\hline \multicolumn{6}{|l|}{ Precision } \\
\hline I. Repeatability & 99.28 & 0.1080 & 0.8556 & 0.0482 & 0.0341 \\
\hline \multicolumn{6}{|l|}{$\begin{array}{l}\text { II. Intermediate } \\
\text { precision }\end{array}$} \\
\hline a. Days & 99.84 & 0.0620 & 0.4606 & 0.0277 & 0.0196 \\
\hline b. Analysts & 99.64 & 0.0500 & 0.4006 & 0.0223 & 0.0158 \\
\hline c. Instruments & 99.08 & 0.5915 & 0.5840 & 0.2645 & 0.1865 \\
\hline Robustness & 99.20 & 0.6697 & 0.6730 & 0.2997 & 0.2120 \\
\hline
\end{tabular}

* mean of six dilutions in triplicate; $S D=$ standard deviation; $C V=$ coefficient of variance; SEx = standard error of mean; and SE $\sigma=$ standard error of standard deviation. 
Table 3: Results of cilostazol determination in tablets

\begin{tabular}{|c|c|c|c|c|c|c|}
\hline \multirow{3}{*}{$\begin{array}{c}\text { Conc. }(\mu \mathrm{g} / \mathrm{ml}) \\
\rightarrow \\
\text { Batch }\end{array}$} & \multicolumn{6}{|c|}{$\%$ found } \\
\hline & \multicolumn{3}{|c|}{ LRE } & \multicolumn{3}{|c|}{ SA } \\
\hline & 10 & 15 & 20 & 10 & 15 & 20 \\
\hline I & 101.70 & 101.20 & 100.60 & 100.40 & 99.93 & 99.35 \\
\hline II & 102.10 & 101.50 & 101.40 & 100.80 & 100.30 & 100.20 \\
\hline III & 100.90 & 100.80 & 101.20 & 99.70 & 99.60 & 99.95 \\
\hline IV & 101.20 & 102.00 & 101.50 & 99.90 & 100.70 & 100.03 \\
\hline V & 102.40 & 101.60 & 100.90 & 101.10 & 100.20 & 99.70 \\
\hline VI & 100.00 & 100.40 & 100.90 & 98.70 & 99.13 & 99.70 \\
\hline Mean & & 101.23 & & & 99.96 & \\
\hline SD & & 0.611 & & & 0.592 & \\
\hline CV & & 0.603 & & & 0.592 & \\
\hline SEx & & 0.144 & & & 0.139 & \\
\hline $\mathrm{SE} \sigma$ & & 0.101 & & & 0.098 & \\
\hline
\end{tabular}

$L R E=$ linear regression equation method and $S A=$ standard absorptivity method

The validated methods were applied to determine cilostazol in tablet dosage form, and the results were $101.23 \%(S D=0.611)$ by LRE method, and $99.96 \%$ (SD $=0.592$ ) by SA method. Mean of standard deviation (SEx) and standard error of standard deviation (SE $\sigma$ ) were far less than acceptable limits (see Table 3). Value of coefficient of variance for robustness was within acceptable limits.

\section{DISCUSSION}

The linear regression equation and standard absorptivity methods have been validated as per ICH guidelines, and results of validation parameters were within acceptable limits. Cilostazol was estimated by LRE and SA methods in tablet dosage form with standard deviation of 0.611 and 0.592 , respectively. On comparing the two methods using the Ftest, the calculated value of $F(1.065)$ was substantially less than the theoretical value at $99 \%$ confidence value; therefore, the methods have comparable precision. Impurities or any other interfering substances with $\lambda_{\max }$ close to that of cilostazol $(258.2 \mathrm{~nm})$ would adversely affect the accuracy of the developed methods.. Further study on possible interfering substances will need to be carried out.

\section{CONCLUSION}

The developed methods for cilostazol are simple, rapid and economical with acceptable accuracy, precision, reproducibility and are robust to slight variations in experimental conditions. Thus, the validated methods may be used for routine analysis of cilostazol as the bulk drug and in tablets and other dosage forms where excipients will not interfere spectrally.

\section{REFERENCES}

1. Hashiguchi M, Ohna K, Nakasawa R, Kishino S, Mochizuki M, Shiga T, Cardiovas Drugs and Therapy, 2004; 18: 211-217.

2. Sweetman SC, Ed, In: Martinadale: The Complete Drug Reference, $33^{\text {rd }}$ Edn, Pharmaceutical Press, USA, 2002; Vol I, pp 258-860.

3. Kishida M, Watanabe $K$, Tsuruoka $T$. Effects of cilostazal in patients with bradycardiac arterial fibrillation. J Cardiol, 2001; 37: 27-33.

4. Madias JE. Cilostazol: an "intermittent claudicatio" remedy for management of third degree $A V$ block. Chest, 2003; 123(4): 979-982.

5. Bramer SL, Tata PN, Vengurlekar SS, and Brisson $\mathrm{JH}$. Method for the quantitative analysis of cilostazol and its metabolites in human plasma using LC/MS/MS. J Pharm Biomed Anal, 2001; 26(4): 637-650.

6. Lestari $A D$, Palupi $T$, Okarina B, Mochammad GY, Indrayanto G. HPLC determination of cilostazol in tablets and its validation. $J$ Liquid Chrom Related Technol, 2004; 27(16): 26032612. 
Basniwal et al

7. Basniwal PK, Srivastava PK, Jain D. Hydrolytic Degradation Profile and RP-HPLC Estimation of Cilostazol in Tablet Dosage Form. Indian $J$ Pharm Sci, 2008; 70(2): 222-224.

8. $\mathrm{ICH}$ "Text on Validation of Analytical Procedures" (International Conference on Harmonization of Technical Requirements for Registration of
Pharmaceutical for Human Use, Geneva, Jul 2000).

9. $\mathrm{ICH}$ "Validation of Analytical Procedure: Methodology" (International Conference on Harmonization of Technical Requirements for Registration of Pharmaceutical for Human Use, Geneva, Jul 2000). 